\title{
Perceptions of Endodontic Treatment Outcomes Provided by Undergraduate Students and Endodontic Specialists
}

\author{
Emilia Karova DMD, Assoc. Prof, PhD, Irina Tsenova DMD, Viktoria Petrova DMD, Alexander \\ Bonchev, DMD, Violeta Dogandzhiyska, DMD, PhD
}

Medical University - Sofia, Bulgaria, Faculty of Dental Medicine, Department of Conservative Dentistry

\section{ABSTRACT}

Introduction A growing interest from investigators and practitioners have been registered in assessing patients' quality of life and satisfaction with effectiveness of provided dental care. Specific treatment-related satisfaction measures have been introduced to recognize individuals' perceptions of root canal treatment outcomes. Methods Two hundred systemically healthy patients with irreversible inflammation of the dental pulp were endodontically treated and filled in anonymously a questionnaire consisting of two parts: 1) personal and demographic information (age, gender, occupation, education, income), and 2) seven semantic differential scales evaluating personal satisfaction two weeks after root canal treatment was completed. Level of satisfaction was assessed by assigning scores from 1 to 10 along continuous bipolar scales, separately for each treated tooth. $\mathbf{R e}-$ sults Very high overall satisfaction was registered in both groups with the scores being higher for patients treated by students but the difference was insignificant $(p=0.068)$. Patients were significantly more pleased with their root canal treatment provided by specialists followed by undergraduate students $(p=0.017)$. On the contrary, satisfaction with treatment cost was significantly lower for those treated by specialists compared to values registered by students' patients $(p<0.0001)$. Conclusions Endodontic treatment provided by undergraduate students and endodontic specialist resulted in an extremely high level of overall satisfaction almost equal for both groups. Treatment painfulness, postoperative esthetics and chewing ability were highly appreciated regardless of the treatment provider but perception of postoperative pleasantness was significantly higher for specialists. Significantly greater satisfaction with the treatment cost was registered in the group treated by students.
Key words: endodontic specialists, endodontic treatment outcome, perception, satisfaction, undergraduate students

*Correspondence to Author:

Dr Viktoria Petrova

Faculty of Dental Medicine, blv. St. G. Sofijski 1, 1431 Sofia, Bulgaria

How to cite this article:

Emilia Karova, Irina Tsenova, Viktoria Petrova, Alexander Bonchev, Violeta Dogandzhiyska. Perceptions of Endodontic Treatment Outcomes Provided by Undergraduate Students and Endodontic Specialists. International Journal of Dental Research and Reviews, 2019, 2:12

\section{eScîPub}

eSciPub LLC, Houston, TX USA. Website: http://escipub.com/ 


\section{Introduction}

Everyday lives of individuals can be significantly affected by the symptoms of different oral disorders. Recently, a growing interest from investigators and practitioners have been registered in assessing patients' quality of life and satisfaction with effectiveness of provided dental care associated with traumatic dental injury ${ }^{1}$, implants ${ }^{2}$, periodontal diseases $^{3}$, orthodontic treatment ${ }^{4}$, caries ${ }^{5}$ and root canal treatment ${ }^{6,7}$.

A common consensus exists about the multidimensional nature of satisfaction with dental treatment and dental care providers ${ }^{8}$. Dentist-patient relationship ${ }^{9-11}$, compliance and treatment outcome ${ }^{12}$ and some sociodemographic factors such as age $^{8,13,14}$, gender ${ }^{13,15}$ and education ${ }^{14}$ can influence patients' perceptions of their treatment. Better understanding of various dimensions of oral health related quality of life can ensure a positive patient-dentist relationship ${ }^{9,10,16}$.

The recognition of patient satisfaction with treatment as an important dimension of quality of health care has led to the introduction of different specific treatment-related satisfaction measures ${ }^{17-20}$. Initially, dental satisfaction questionnaires assessed some major dimensions of patient satisfaction but many of these items were abstract and gave a thirdperson generalized opinion about dentistry and dentists rather than first-person rating of a specific dentist ${ }^{18}$. Other scales were related to negatively and positively worded items ${ }^{21}$, but none of these questionnaires seemed to be appropriate for assessing patients' perception of and satisfaction with a particular health care and care provider but not the profession in general ${ }^{17}$. This led to the development and application of The Dental Visit Satisfaction Scale by Corah et al. ${ }^{20}$ which was based on the Medical Interview Satisfaction Scale of Wolf et al. ${ }^{22}$ and was adapted for measurement of cognitive, affective, and behavioral satisfaction, as well as an overall satisfaction score of the dental patient.
Semantic differential scales are another method, firstly introduced by Osgood et al. ${ }^{23}$, which can be successfully used for rating of endodontic treatment outcomes. Each subject's level of satisfaction is rated from 1 to 10 on a series of continuous bipolar scales defining several dimensions related to endodontic treatment, such as cost, pain, and function. Results of surveys using such investigation instrument might improve the general public's perception of endodontic treatment by identifying the factors related to satisfaction with $\mathrm{it}^{24}$.

Different treatment providers can perform the root canal treatment but still data are insufficient concerning the effect of their training and experience on patients' satisfaction with treatment outcomes ${ }^{6,7}$.

Based on the increasing interest of the dental community to better understand the impact of quality of root canal treatment on patients' satisfaction with it, we designed the current survey. The aim of this study was to assess patients' perceptions of the endodontic treatment outcomes provided by undergraduate students and endodontic specialists. The null hypothesis tested was that there would be no significant difference in the satisfaction of endodontic patients treated by dental care providers with different training experience.

\section{Materials and methods}

The study was conducted in the Department of Conservative Dentistry, Faculty of Dental Medicine, Medical University, Sofia, Bulgaria. The endodontic treatment was provided by fourth-year and fifth-year students in the course of their clinical exercises and by five endodontic specialists.

Two hundred systemically healthy, mentally fit and legally capable of signing an informed consent patients were randomly selected and participated voluntarily. All adults aged 18 years and more who were with diabetes mellitus, blood disorders, dialysis, immunodeficiency, pregnancy, trauma, implants and orthodontic 
treatment were excluded from the monitoring. A radiographically examined and the ones with consent form describing the aim of the study previous endodontic treatment and signs of and the methods to be used was signed by all untreated apical periodontitis were excluded approved participants. A primary endodontic from the observation. The study protocol was treatment was planned for all of them because approved by the ethical committee of the of an irreversible inflammation of the dental university.

pulp. All teeth were clinically and

\section{The provided endodontic treatm ent was:}

\begin{tabular}{llllllllll}
1 & 2 & 3 & 4 & 5 & 6 & 7 & 8 & 9 & 10 \\
\hline
\end{tabular}

Expen sive

In expen sive

\begin{tabular}{cccccccccc}
$\square$ & $\square$ & $\square$ & $\square$ & $\square$ & $\square$ & $\square$ & $\square$ & $\square$ & $\square$ \\
1 & $\mathbf{2}$ & $\mathbf{3}$ & $\mathbf{4}$ & $\mathbf{5}$ & $\mathbf{6}$ & $\mathbf{7}$ & $\mathbf{8}$ & $\mathbf{9}$ & $\mathbf{1 0}$ \\
\hline
\end{tabular}

Time-consuming

Quick

\begin{tabular}{llllllllll}
1 & 2 & 3 & 4 & 5 & 6 & 7 & 8 & 9 & 10 \\
\hline
\end{tabular}

Painful

\begin{tabular}{llllllllll}
\hline & $\square$ & $\square$ & $\square$ & $\square$ & $\square$ & $\square$ & $\square$ & $\square$ & $\square$ \\
1 & 2 & 3 & 4 & 5 & 6 & 7 & 8 & 9 & 10 \\
\hline
\end{tabular}

Poor esthetics of the restoration

$\begin{array}{llllllllll}\square & \square & \square & \square & \square & \square & \square & \square & \square & \square\end{array}$

\begin{tabular}{llllllllll}
1 & 2 & 3 & 4 & 5 & 6 & 7 & 8 & 9 & 10 \\
\hline
\end{tabular}

With poor chewing ability

With good chewing ability

\begin{tabular}{llllllllll}
$\square$ & $\square$ & $\square$ & $\square$ & $\square$ & $\square$ & $\square$ & $\square$ & $\square$ & $\square$ \\
1 & 2 & 3 & 4 & 5 & 6 & 7 & 8 & 9 & 10 \\
\hline
\end{tabular}

Unpleasant

Pleasant

II. The provided endodontic treatment makes me feel:

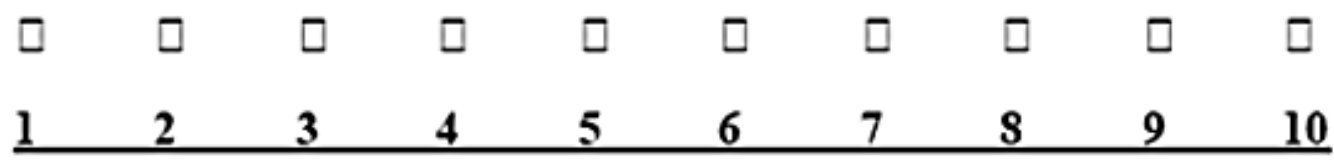

Very dissatisfied

Very satisfied 
Table 1 Distribution of all participants and means of their overall satisfaction with treatment according to the age, gender, education, occupation and income

\begin{tabular}{llcc}
\hline Variable & Ratio & $\begin{array}{c}\text { Overall satisfaction } \\
\text { (\%) }\end{array}$ & $\begin{array}{c}\text { Oeans } \pm \text { SE) } \\
\text { Age (years) }\end{array}$ \\
& $18-30-40$ & 18.52 & $9.06 \pm 1.692$ \\
& $40-50$ & 30.56 & $9.57 \pm 1.237$ \\
& $50-60$ & 17.79 & $9.25 \pm 1.765$ \\
& $>60$ & 12.67 & $9.43 \pm 0.976$ \\
Gender & Male & 20.46 & $9.53 \pm 0.513$ \\
\hline Education & Female & 44.05 & $9.25 \pm 1.156$ \\
& Primary & 55.95 & $9.07 \pm 1.754$ \\
\hline Occupation & Secondary & 5.2 & $6.75 \pm 1.258 *$ \\
& High & 44.67 & $9.16 \pm 1.725$ \\
& Student & 50.13 & $9.25 \pm 1.238$ \\
& Unemployed & 3.82 & $7.83 \pm 2.714$ \\
& Worker & 7.64 & $8.50 \pm 2.111$ \\
& Specialist & 50.98 & $9.23 \pm 1.575$ \\
& Retired & 18.37 & $9.17 \pm 1.284$ \\
& Low & 19.19 & $9.43 \pm 1.679$ \\
\hline & Middle & 28.08 & $8.45 \pm 1.532$ \\
& High & 64.84 & $9.47 \pm 1.166$ \\
& & 7.08 & $8.91 \pm 2.982$ \\
\hline
\end{tabular}

* Significant difference $(\mathrm{P}<0.05)$, Kruskal-Wallis test.

Table 2 Mean values of patients' perceptions of endodontic treatment outcomes provided by different dental care providers

\begin{tabular}{lccc}
\hline Semantic differential scale & Students & Specialists & P-value \\
\hline Treatment cost* & $8.61 \pm 2.195$ & $5.59 \pm 2.353$ & $<\mathbf{0 . 0 0 0 1}$ \\
Treatment duration & $6.32 \pm 2.889$ & $6.74 \pm 2.364$ & 0.313 \\
Treatment painfulness & $8.14 \pm 2.517$ & $7.81 \pm 2.521$ & 0.413 \\
Postoperative esthetics & $8.87 \pm 1.816$ & $9.05 \pm 1.517$ & 0.501 \\
Postoperative chewing ability & $8.85 \pm 1.772$ & $9.09 \pm 1.583$ & 0.371 \\
Postoperative pleasantness * & $7.55 \pm 2.175$ & $8.39 \pm 2.201$ & $\mathbf{0 . 0 1 7}$ \\
Overall satisfaction & $9.39 \pm 1.279$ & $9.00 \pm 1.378$ & 0.068 \\
\hline
\end{tabular}

* Determinant with a significant difference $(\mathrm{P}<0.05)$ between the two groups of treatment providers $($ Mann-Whitney $U$ test)

On the final treatment visit patients filled in anonymously a questionnaire consisting of two parts: 1) personal and demographic information (age, gender, occupation, education, income), and 2) semantic differential scales evaluating personal satisfaction two weeks after root canal treatment was completed. Participants were asked to define their perceptions of treatment outcome by rating its different aspects and their relative importance. Seven semantic differential scales were used to estimate the cost, the time involved, the pain during the procedure, the 
aesthetics and chewing ability of the treated tooth, the postoperative pleasantness of the treatment and the overall satisfaction with the provided dental care (Fig. 1). The subjects were asked to characterize their level of satisfaction by assigning scores from 1 to 10 along continuous bipolar scales, separately for each treated tooth.

Data were analyzed using SPSS software version 17.0. Frequency distribution with means and standard errors of means was registered for continuous variables. Satisfaction with root canal treatment amongst different categorical variables was investigated using nonparametric statistics.

\section{Results}

One hundred and fifty-seven patients completed the study as 17 did not appear on their second visit, 18 did not finish the treatment and 8 refused to fill in the questionnaire. Seventy-seven of the participants were treated by undergraduate students and 80 - by endodontic specialists.

The distribution of all participants according to their age, gender, education, occupation and income is presented in Table 1.

Table 2 presents the mean values of patients' perceptions of endodontic treatment outcomes provided by different dental care providers. Participants defined their satisfaction with the root canal treatment by rating it with responses ranging from 1 (most unfavourable) to 10 (most favourable). Very high overall satisfaction was registered in both groups with the scores being higher for patients treated by students (9.39) followed by those treated by specialists $(9.00)$ but the difference was insignificant $(p=0.068)$. Patients were significantly more pleased with their root canal treatment provided by specialists followed by undergraduate students $(p=0.017)$. On the contrary, satisfaction with treatment cost was significantly lower for those treated by specialists (5.59) compared to values registered by patients treated by students (8.61) $(p<0.0001)$. The calculated mean values for treatment painfulness, postoperative esthetics and chewing ability revealed very high satisfaction with the treatment provided by both groups as the scores exceeded 8, although differences remained insignificant.

Distribution of overall satisfaction among all participants according to their age, gender, education, occupation and income is presented in Table 1.

\section{Discussion}

The present study was designed to assess patients' perceptions of endodontic treatment outcomes and the influence of experience of different dental care providers on them. Satisfaction with treatment provided by undergraduate students and endodontic specialists was analyzed with the assumption that this two groups reflect ideally the opposing conditions considering training abilities and skillfulness. Only patients with primary endodontic treatment of irreversible inflammation of the dental pulp were included into the observation with the intension to restrict the chance of exacerbations and prolonged treatment.

Patients' satisfaction with treatment is considered a legitimate goal of health and dental care ${ }^{17-20}$, a prerequisite of quality care and compliance of patients ${ }^{25}$. High quality results cannot be considered in patients unsatisfied with the treatment and dentist's attitude received and still having some complaints from pain and lack of aesthetics and functional ability of the treated teeth. Our results support this statement as the overall satisfaction of all participants was very high based on their high appreciation of the painless procedures and postoperative aesthetics and chewing ability of teeth. These findings are in agreement with the results acquired by Dugas et al. $^{6}$ who were the first to assess the endodontic-related quality of life of patients treated by generalists and endodontists. 
The general satisfaction of the provided dental care by students and specialists was rated almost equally and based on this our null hypothesis was confirmed. The received results were surprising for us as we expected higher appreciation for specialists being more skillful and proficient. At the same time, even the high treatment cost of specialists did not make patients feel unsatisfied by the overall results acquired. Our findings are in contrast with the results obtained in the studies of other researchers $6,7,20$ and probably can be explained with the lower expectations of students' patients compared to that of specialists' ones and their readiness to rate students' work with higher scores and thus give them more courage and confidence in their abilities.

Expectedly, the lowest scores acquired were that for the cost of specialists' treatment and the difference was significant when compared to the price of students' manipulations. A great contrast was registered between the two groups as the dental school patients participating in this study represented a lower socioeconomic status (52\% workers, $23 \%$ retired) and highly appreciated the low cost students' treatment. Our data reflect the results of other observations that compare the cost of a treatment provided by students, postgraduates and specialists ${ }^{6,7}$.

Despite the lower rating for cost, treatment duration and painfulness, the scores for the postoperative pleasantness registered in the specialists' group were significantly higher than these in the group treated by students. These results can be linked to some important determinants of patients' satisfaction, like better communication skills of endodontists, their willingness to respond to patient's fears and expectations and capability to give comprehensive information about treatment and expected outcomes. The significance of the interpersonal skills of the dentists for perceptions of provided treatment is pointed out in the work of Corah et al. ${ }^{20}$, as well.

\section{Conclusion}

Within the limitations of this study, endodontic treatment provided by undergraduate students and endodontic specialist resulted in an extremely high level of overall satisfaction. Although unqualified, undergraduate students presented as a reliable provider of endodontic care and acquired scores almost equal to that of specialists. Treatment painfulness, postoperative esthetics and chewing ability were highly appreciated regardless of the treatment provider but perception of postoperative pleasantness was significantly higher for specialists. Significantly greater satisfaction with the treatment cost was registered in the group of patients treated by students.

\section{Acknowledgements}

The authors deny any conflicts of interest related to this study.

\section{References}

1. Dame-Teixeira N, Alves LS, Ardenghi TM, et al. Traumatic dental injury with treatment needs negatively affects the quality of life of Brazilian schoolchildren. Int J Paed Dent 2012; 23:266273 doi: 10.1111/ipd.12002.

2. Wolfart S, Moll D, Hilgers R-D, et al. Implant placement under existing removable dental prostheses and its effect on oral health-related quality of life. Clin Oral Impl Res 2012; 0:1-6 doi: $10.1111 / \mathrm{clr} .12030$

3. Al Habashneh R, Khader YS, Salameh S. Use of the Arabic version of Oral Health Impact Profile14 to evaluate the impact of periodontal disease on oral health-related quality of life among Jordanian adults. J Oral Sci 2012; 54: 113-120.

4. Manjith CM, Karnam SK, Manglam S, et al. Oral Health-Related Quality of Life (OHQoL) among adolescents seeking orthodontic treatment. J Contemp Dent Practice 2012; 13: 294-298.

5. Alves LS, Dame-Teixeira N, Susin C, et al. Association among quality of life, dental caries treatment and intraoral distribution in 12-year-old South Brazilian schoolchildren. Community Dent Oral Epid 2013; 41, 22-29.

6. Dugas NN, Lawrence HP, Teplitsky $P$, et al. Quality of life and satisfaction outcomes of endodontic treatment. J Endod 2002; 28, 819827. 
7. Hamasha AA, Hatiwsh A. Quality of life and satisfaction of patients after nonsurgical primary root canal treatment provided by undergraduate students, graduate students and endodontic specialists. Int Endod J 2013; 46, 1131-1139.

8. Newsome PR, Wright GH. A review of patient satisfaction: 2. Dental patient satisfaction: an appraisal of recent literature. Br Dent J 1999; 186:166-170.

9. Sampogna $F$, Johansson $V$, Axtelius $B$, et al. Quality of life in patients with dental conditions: comparing patients' and providers' evaluation. Community Dent Health 2009; 26:234-238.

10. Yamalik N. Dentist-patient relationship and quality care 3. Communication. Int Dent J 2005;55:254-256.

11. Schouten BC, Eijkman MA, Hoogstraten J. Dentists' and patients' communicative behavior and their satisfaction with the dental encounter. Community Dent Health 2003; 20:11-15.

12. Sondell K, Soderfelt B, Palmqvist S. Dentistpatient communication and patient satisfaction in prosthetic dentistry. Int J Prosthodont 2002;15: 28-37.

13. Carr-Hill R. The measurement of patient satisfaction. J Public Health 1992;14: 236-49.

14. Sitzia J, Wood N. Patient satisfaction: a review of issues and concepts. Soc Sci Med 1997; 45:1829-1843.

15. Skaret E, Berg E, Raadal M, et al. Factors related to satisfaction with dental care among 23years olds in Norway. Community Dent Oral Epidemiol 2005; 33:150-157.

16. Ayala-Luis J, Johansson V, Sampogna F, et al. A multivariable analysis of patient dental satisfaction and oral health-related quality-of-life. A cross-sectional study based on DVSS and OHIP-14. Acta Odontologica Scandinavica, 2014; 72: 187-193

17. Ware, J. E., Jr., Snyder, M. K, Wright, W. R. Some Issues in the Measurement of Patient Satisfaction with Health Care Services. 1977; Rand Corp., Santa Monica, Calif. (P-6021).

18. Davies, A. R., Ware, J. E., Jr. Development of a Dental Satisfaction Questionnaire for the Health Insurance Experiment. 1982; Rand Corp., Santa Monica, Calif. (R-2712-HHS).

19. Chapko MK, Bergner M, Green K, et al. Development and validation of a measure of dental patient satisfaction. Med Care 1985; 23:39-49.

20. Corah NL, O'Shea RM, Pace LF, et al. Development of a patient measure of satisfaction with the dentist: the dental visit satisfaction scale. J Behav Med 1984; 7:367-373.
21. Hengst, A., Roghmann, K. The two dimensions in satisfaction with dental care. Med Care 1978; 16 : 202-213.

22. Wolff, M. H., Putnam, S. M., James, S. A., et al. The medical interview satisfaction scale: Development of a scale to measure patient perceptions of physician behavior. J. Behav Med 1978; 1: 391-401.

23. Osgood C, Suci G, Tannenbaum P. The measurement of feeling. Urbana: The University of Illinois Press, 1957.

24. American Association of Endodontists. Public Education Report. Surveys document more people choosing root canal therapy over extraction, 1987.

25. Newsome PR, Wright GH. A review of patient satisfaction: 1. Concepts of satisfaction. $\mathrm{Br}$ Dent J 1999; 186:161-165. 